\title{
Student responses to being taught physics in isizulu
}

AUTHOR:

Naven Chetty ${ }^{\top}$

\section{AFFILIATION:}

${ }^{1}$ School of Chemistry and

Physics, University of KwaZulu-

Natal, Pietermaritzburg,

South Africa

\section{CORRESPONDENCE TO:}

Naven Chetty

EMAIL:

ChettyN3@ukzn.ac.za

POSTAL ADDRESS:

School of Chemistry and

Physics, University of KwaZulu-

Natal, P0 Box X01, Scottsville

3209 , South Africa

DATES:

Received: 13 Sep. 2012

Revised: 18 Jan. 2013

Accepted: 26 Mar. 2013

\section{KEYWORDS:}

isiZulu; physics; university;

UKZN; survey; language

\section{HOW TO CITE:}

Chetty N. Student responses to being taught physics in isizulu. S Afr J Sci. 2013;109(9/10), Art. \#2012-0016, 6 pages. http://dx.doi.org/10.1590/ sajs.2013/20120016 (c) 2013. The Authors. Published under a Creative Commons Attribution Licence.
The University of KwaZulu-Natal is in the process of formulating a language policy to introduce teaching and learning in isizulu as well as in English to improve throughput and increase the number of graduates. The aim of this study was to determine if this policy is feasible within the discipline of physics. Critical engagement with students and a literature search allowed the determination of the potential gains and pitfalls of such a language introduction. The study also provides some useful insight into student contexts, schooling history and their perceptions of being taught in their vernacular. The inconsistent use of isizulu words to translate basic physics words will require the development of a common vocabulary for teaching physics in isizulu.

\section{Rationale and motivation}

The purpose of this study was to determine the feasibility of teaching physics in isizulu at the University of KwaZulu-Natal (UKZN). Various teaching and learning difficulties are experienced by science teachers and students in a cross-cultural educational environment such as those commonly found in developing countries. ${ }^{1}$ The student problems include: lack of ability (a consequence of varying and sometimes inadequate high school education), poor background (often related to under-resourced schools and under-qualified teachers), poor motivation (a direct consequence of the high poverty threshold), slow cognitive development, weak vocabulary and poor comprehension of English (most students speak English as a second language) and poor study habits. ${ }^{1}$

Logan², however, pointed out that a student problem attributed to language at one institution was found to exist at another institution without the same language 'problem'. Most developed countries have at some stage dissected language issues and their impact on performance; however, in South Africa, very few studies have been conducted to determine the extent to which language influences performance, and, more specifically, performance in Physics.

Research has shown consistently that traditional lecture methods, in which lecturers talk and students listen, dominate university classrooms. ${ }^{3}$ By and large these lectures are predominantly in English and thus challenge the second-language English speaker. English lectures may also hinder the second-language speaker from participating in active learning. ${ }^{3}$ Analysis of the literature ${ }^{4}$ suggests that students must do more than just listen to lecturers: they must read, write, discuss, or engage in solving problems. Most importantly, to be actively involved, students must engage in higher-order thinking tasks such as analysis, synthesis and evaluation. It must therefore be determined if students perform better at these tasks in their own vernacular (isizulu) than in English.

In order to answer this question, it is imperative to gauge student perceptions to being taught in isizulu, before implementation. A survey was therefore undertaken of level one Physics students on the introduction of isizulu as a language of teaching and learning physics. The survey took into account age, gender, living conditions and schooling background to provide a holistic representation of the respondents.

An excerpt from Whorf's widely quoted paragraph ${ }^{5}$ highlights the importance of the linguistic component in teaching and learning:

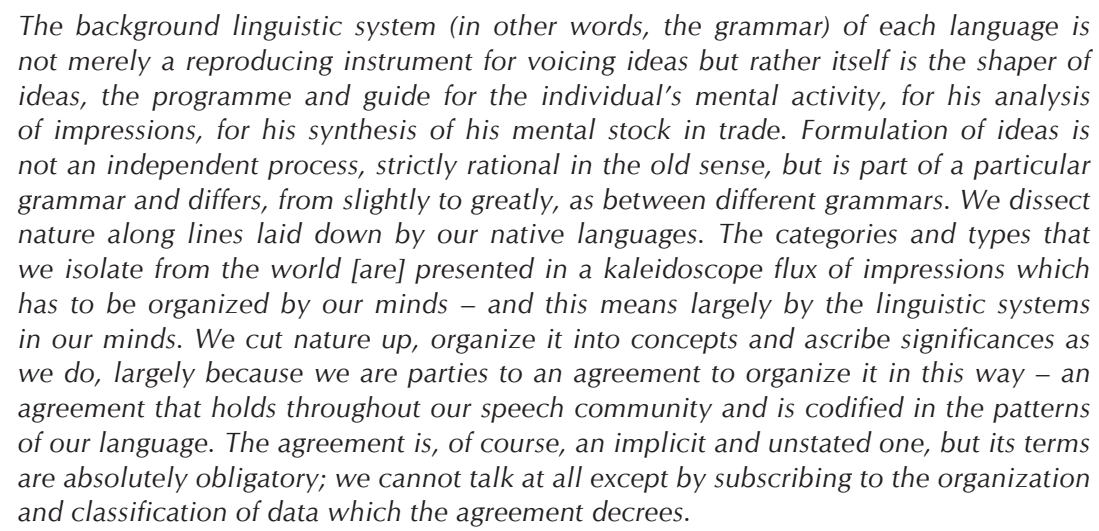

To rephrase, Whorf is implying that the way an ethnic group classifies events happening around them is manifested in the language of the group. Logan ${ }^{1}$ has shown that different languages require a different classification and so it is difficult to translate from one language to another and preserve the meaning. A study by Whorf illustrated his hypothesis with examples in which important concepts in a language have different words or pronunciations to indicate different shades of meaning.

The language problems experienced in South African education reflect Whorf's examples. The students' entire conceptual framework is built in their own language, far different from the scientific framework. They often start school being taught in their own language, English is gradually introduced and, much later, science is taught in English. Thus science concepts are retained along with the traditional concepts. ${ }^{1,6-8}$

In a large (approximately 400 students) level one Physics class at UKZN it is not impossible to imagine a representation of our country's 11 official languages. Thus, according to Whorf ${ }^{6}$ and Logan ${ }^{9}$, there must be at least 
11 interpretations of each lecture as the students fit the new concepts into their traditional linguistic framework. One problem in learning a second language is interference from the first, which will also occur with science as a second culture, as traditional concepts creep in and lead to misconceptions. ${ }^{6,9}$

This study is critical because much of Whorf's theories have fallen out of favour with linguists, ${ }^{10,11}$ who comment that translation is possible between all languages, that people can think without needing a linguistic framework and that there are many similarities in all languages. This study is premised on Whorf's hypothesis being correct and thus the goal is to develop measures that will help students with the language of instruction in level one Physics and subsequently help improve their overall performance. To test the linguistic component of Whorf's hypothesis, English-isizulu translations of common physics words were performed to determine if a consistent vocabulary exists.

Horton ${ }^{12}$ examined patterns in traditional African thought and Western science. His fundamental finding was that in the traditional culture 'there was no developed awareness of alternatives to the established body of theoretical tenets'. In scientifically orientated cultures there is a highly developed awareness of the existence of alternatives. The pedagogical implications of this finding are not discussed; however the finding does point to students from cross-cultural tenets benefiting from an explanation of the Western scientific approach. Physics introduces a further complication - the comprehension of words commonly used in a Physics classroom. Jones ${ }^{13}$ showed that even among English-speaking students, the majority of science students did not understand some words or phrases, such as 'as a consequence', 'includes', 'essential', 'definitely' and 'contradictory'. Research by Jones ${ }^{13}$ and Friere ${ }^{14}$ infers that a student's culture has a positive impact on science learning and teaching. This approach determines the concepts that already exist in the student's language, the concepts that do not exist and the concepts that differ. The concepts which do not exist can then be introduced with a strong emphasis placed on the relevance of the concept. The main reasons these concepts do not exist in vernacular language is that a need does not exist for them. The greatest problem with curriculum development is that concepts can differ and students equate a scientific concept with a traditional one which may be radically different. ${ }^{9,13-15}$

Jones ${ }^{13}$ suggests that this issue of concepts is an important point that lecturers should capitalise on. They need to understand the traditional concept and its area of applicability and show students how traditional concepts and scientific concepts lead to the same pathway within an area of applicability. These traditional concepts correspond to students' everyday experiences of language. The lecturer must then gradually show shortcomings of the traditional theory and explain why the need arises for the scientific approach; however, the language of doing so is not necessarily English.

Williams ${ }^{15}$ considered the underestimated role that language plays in physics. Physics, like all natural sciences, involves the observation of naturally occurring phenomena, the quantification of the observables and the synthesis of the data into theories. All of these components inherently depend on spoken and written communication in ordinary language - a fact that is often overlooked for second-language speakers. A cause of further complication is the inconsistent use of 'physics language', especially in introductory textbooks, which exacerbates the language issues encountered by readers for whom English is not a first language.

Many African students experience problems in pattern perception and in visualising real or theoretical three-dimensional orientations, as a consequence of a traditional upbringing..$^{12,16,17}$ Thus Lodhi' ${ }^{16}$, Horton ${ }^{12}$ and Whittle ${ }^{17}$ suggest that many of the students faced with these problems find themselves living side-by-side in two vastly different worlds.

This situation, as well as the further problem of dialect variations in the English language, is discussed in detail by Fogel and Ehrs ${ }^{18}$. Even though one considers English to be commonly spoken, several dialects can exist which generally reflect cultural, regional and ethnic differences. These differences manifest in various ways: how particular words are pronounced, how sentences are structured grammatically and which words are chosen to reflect certain ideas. It must be noted that both English and isizulu are subject to dialect differences.

As can be seen from the literature, there seem to be numerous loose ends. Thus this study is critical, at least in a South African context given concerns with throughput and skills development, in understanding the role of language and its connotations (especially in tradition) on cognitive development.

\section{Methodology}

This paper is focused on ascertaining students' perceptions to being taught in their vernacular. The results will also pave the way forward in answering the ultimate research question: what impact does teaching and learning have on throughput? Qualitative questions were constructed using the established qualitative procedures of Bogden and Biklen ${ }^{19}$. Qualitative data emerged from observed instances during interactions with researcher and students as well as from questionnaires and observational notes. Written questionnaires about the language of instruction were utilised by asking a number of open-ended questions that allowed for variation..$^{20}$

An area of basic research in second language acquisition is the identification and description of learning strategies used by language learners and the correlation of these strategies with other learner variables such as proficiency level, age, gender and motivation. ${ }^{21-24}$ This study also investigated the effect of the task itself on the selection and use of learning strategies, including the influence of the target language. ${ }^{25-28}$ In this study it was assumed all students answered all the survey questions honestly.

Most descriptive studies have employed a questionnaire developed by Oxford ${ }^{27}$ : the Strategy Inventory for Language Learning (SILL). This questionnaire has been used extensively to collect data on large numbers of mostly foreign language learners. ${ }^{24,26,29-33}$ The SILL is a standardised measure with versions for speakers of a variety of languages, and as such can be used to collect and analyse information about large numbers of language learners. ${ }^{26} \mathrm{~A}$ version of SILL adapted for the South African isiZulu context was used in this study.

\section{Results and discussion}

The isizulu-speaking cohort of the level one Physics class of 2011 was surveyed in this study. Two streams of student groups were investigated. Stream 1 was the mathematical sciences stream of students - these students are contenders to major in Physics. A total of 47 students (38 male and 9 female) in this stream responded, translating to approximately $45 \%$ of the total number of registered students in this stream. Stream 2 was those students who take Physics as an elective or who require a year of Physics for a life sciences major. A total of 78 students (44 male and 34 female) responded - approximately $37 \%$ of the registered students.

The survey comprised 39 questions in English with most questions requiring justification of the response provided. The survey was administered during the students' free afternoons over 2 weeks so that they had no time constraints. Most students (92\%) answered anonymously. The students were able to ask a postgraduate isizuluspeaking demonstrator for help if they did not understand the questions or if they needed elaboration. The researcher was also present to help students if required.

The survey had three main thrusts. The first section (see Table 1) aimed to establish the student's context - information on age, home lifestyle, family members and access to basics such as water and electricity. The second section (see Table 2) requested more information about the student's schooling, especially with respect to language of instruction, access to basics such as water and electricity at school, and availability of laboratories and libraries. The final section (see Table 3) gathered information on the student's UKZN Physics experience and their feelings on being taught physics in isizulu.

From Table 1 it is evident that most of the students live in formal homes and have access to basics such as water and electricity. Of concern here is the large percentage of those students living in informal settlements 
that do not have both electricity and running water. The information provided also suggests that there are a number of people living in the homesteads but there is no evidence of overcrowding.

Table 1: Student responses to questions on their personal environment

\begin{tabular}{l|c|c}
\hline \hline Survey question & $\begin{array}{c}\text { Stream 1 } \\
\text { (\%) }\end{array}$ & $\begin{array}{c}\text { Stream 2 } \\
\text { (\%) }\end{array}$ \\
\hline \hline Do you live in an informal or formal settlement? & \multicolumn{2}{|l}{} \\
\hline Informal & 19 & 10 \\
\hline Formal & 81 & 90 \\
\hline How many family members live with you at home? & \multicolumn{2}{|l}{} \\
\hline Up to 5 people & 55 & 51 \\
\hline $5-10$ people & 30 & 39 \\
\hline More than 10 people & 15 & 10 \\
\hline Do you have electricity at home? & \multicolumn{1}{|l}{} \\
\hline Yes & 89 & 95 \\
\hline No & 11 & 5 \\
\hline Do you have clean running water at home? & \multicolumn{2}{|l}{} \\
\hline Yes & 85 & 90 \\
\hline No & 15 & 10 \\
\hline
\end{tabular}

Table 2 addresses concerns of poor schooling environments and poor cognitive development - issues that can be misconstrued as language problems. Most students were from schools with access to basics such as electricity and water. However, $79 \%$ of the students encountered and accessed libraries and laboratories for the first time at university.

Most students interviewed post-survey (79\% of both streams) expressed not having used or had access to computers until they enrolled at university. This finding is, however, not significant enough to account for any poor performance because understanding physics is not dependent on using a computer. Orientation which is now compulsory for all firstyear students in the College of Agriculture, Engineering and Science at UKZN caters for these issues by offering library and local area network orientation programmes.

The lack or absence of laboratories and laboratory experiments is more problematic as it directly relates to the subject and may well account for a substantial deficit in performance. Discussions with the students indicate that they struggle with the use of equipment and fail to observe proper lab protocols or follow basic laboratory methodologies as they were never exposed to these at school. Being confronted with these additional challenges at university level, when already facing major adjustments from high school, definitely affects their performance. These students also often face reprimands from laboratory demonstrators or lecturers who assume when the students have not understood the practical, that they did not read the manual, when in fact they had read the manual but became confused as to which piece of equipment to use, how to connect wires in circuits or even where to switch on the apparatus. The reasons for their lack of knowledge are not interrogated by instructors and the easier assumption is that a language barrier is the cause. Thus instructors may be motivating for teaching in isizulu under a false assumption that it will address the primary problems described above.

Interesting to note is that the students who were taught entirely in English at school did not want to be taught in isizulu at school as they believed English would help them at university. Students who were taught in both languages indicated that they would have preferred to have been taught in a single language - English - as they were often confused by teachers who drifted off the subject when they could not explain the material adequately in English. Because the school syllabus currently allows for many descriptive applications ${ }^{34}$ to be discussed and thus easily explained in isizulu, students felt the teachers spent too much time on these descriptive applications and too little time on the actual science. They had also become accustomed to school teachers explaining some concepts in English and others in isizulu, which hampered their university communication as they felt it difficult to ask questions or interact with a lecturer in English, because of their poor grasp of the language. Thus they believed that they should have been taught in English at school to better equip them for studying physics at university.

\section{Table 2: Student responses to questions on their previous schooling}

\begin{tabular}{|c|c|c|}
\hline Survey question & $\begin{array}{c}\text { Stream } 1 \\
(\%)\end{array}$ & $\begin{array}{c}\text { Stream } 2 \\
(\%)\end{array}$ \\
\hline \multicolumn{3}{|l|}{ Where is your school situated? } \\
\hline Urban (town) & 42 & 41 \\
\hline Rural & 58 & 59 \\
\hline \multicolumn{3}{|l|}{ Did you have electricity at school? } \\
\hline Yes & 89 & 97 \\
\hline No & 11 & 3 \\
\hline \multicolumn{3}{|l|}{ Did you have clean running water at school? } \\
\hline Yes & 89 & 93 \\
\hline No & 11 & 7 \\
\hline \multicolumn{3}{|l|}{ Did you have a library at school? } \\
\hline Yes & 49 & 42 \\
\hline No & 51 & 58 \\
\hline \multicolumn{3}{|l|}{ Did you have a physics laboratory at school? } \\
\hline Yes & 43 & 43 \\
\hline No & 57 & 57 \\
\hline \multicolumn{3}{|l|}{ Did you do physics experiments at school? } \\
\hline Yes & 36 & 32 \\
\hline No & 64 & 68 \\
\hline \multicolumn{3}{|l|}{ Did you have physics textbooks and study materials? } \\
\hline Yes & 83 & 87 \\
\hline No & 17 & 13 \\
\hline \multicolumn{3}{|l|}{ In what language were you taught Physics? } \\
\hline English only & 47 & 40 \\
\hline isizulu only & 0 & 3 \\
\hline A mixture of both English and isizulu (code-switching) & 53 & 57 \\
\hline \multicolumn{3}{|c|}{ Did you receive any extra (paid) tuition for Physics in Grade $12 ?$} \\
\hline Yes & 62 & 44 \\
\hline No & 38 & 56 \\
\hline
\end{tabular}

Table 3 shows the students' university (specifically Physics) context. It can be seen that the bulk of the students are funded by financial aid. Students commented that this funding method was inadequate because of its tentative nature. Students need to re-apply each year and most were concerned that reduced government funding or a funding model change would result in their financial aid being revoked and them not being able to continue with their studies. These students agreed that this concern increased the pressure they felt, which could also contribute to their poor performance. Although ironically, the students funded through other means felt exactly the same as those funded by financial aid - they were also concerned about how they would fund their studies in subsequent years and in some cases even about how they could pay their current year's fees. This problem is in no way related to language; however, it may often be overlooked and poor performance by students is simply linked to language problems. Language changes will not address these issues; thus any discussions on language need to consider the students holistically, before radical implementation occurs.

The students were then asked a series of open-ended questions to gauge their reasons for opting to take Physics as well as their perceptions on being taught physics in isizulu. The responses of Streams 1 and 2, discussed below, were combined to give a better overall view of the students' responses. 
Table 3: Student responses to questions about their university environment

\begin{tabular}{l|c|c}
\hline \hline Survey question & $\begin{array}{c}\text { Stream 1 } \\
\text { (\%) }\end{array}$ & $\begin{array}{c}\text { Stream 2 } \\
\text { (\%) }\end{array}$ \\
\hline \hline Where are you living while at university? & & \\
\hline Residence & $73^{+}$ & $63^{+}$ \\
\hline Off-campus accommodation & 19 & 24 \\
\hline At home & 5 & 9 \\
\hline How are you paying for your studies? & & \\
\hline Financial aid & $45^{+}$ & $44^{+}$ \\
\hline Family & 36 & 41 \\
\hline Bursary & 9 & 9 \\
\hline Other & 2 & 2 \\
\hline
\end{tabular}

totals less than $100 \%$ indicate a null student response to the question.

\section{What was your reason for choosing to study physics?}

In Stream 1, approximately $40 \%$ of the students are doing Physics as part of an Engineering degree. Their responses indicate that they enjoyed the subject matter and found that it helps them better understand their Applied Mathematics curriculum. Approximately $40 \%$ of the students in Stream 1 intended to major in Physics. The remaining 20\% of respondents in Stream 1 are taking Physics as a gateway to other career paths such as Medical or Engineering degrees. In Stream 2, 90\% of the students are studying Physics because it is a prerequisite for their modules in life sciences or agricultural sciences. The remaining $10 \%$ are studying Physics as a gateway to other fields of study.

\section{What were the main adjustments between physics in school and at university?}

A high number (40\%) of students cited an increase in the workload as the main adjustment between school and university physics. About 10\% found it difficult to cope with university physics mainly because of the language barrier. English-only lectures made communication difficult as the students were not used to a solely English environment. Most of the $10 \%$ were fearful of asking questions in class because of their poor English and thus their misconceptions remained, which greatly affected their performance.

Half $(50 \%)$ of the students struggled with being expected to complete the experiments during the practicals by themselves in a fixed period of time, after never having been in a laboratory before.

At least $20 \%$ said that both their physics knowledge and marks had improved and that they found physics at university more interesting because they now had unlimited access to books from the library. Some students reported that they found regular assessments to be difficult because they were not used to an environment of constant studying and testing.

\section{Would you understand physics better if your study materials and notes were in isizulu?}

A small number (14\%) of students believed that they would understand physics better if the materials were in isizulu because they felt they would understand the content better if it were in their own language.

About $44 \%$ of the respondents were against learning materials being in isizulu, with their main concern being that confusion may arise because isizulu does not have translations for most of the English terms used in physics. A further $42 \%$ of the students were unsure or hesitant as they felt that it would make no difference to their performance as they had to study hard to understand the physics regardless if the language.

Are the labs easier to understand if they are explained to you in isizulu?

Nearly $85 \%$ of students believed that their understanding would improve if they could ask questions in the laboratory in isizulu with the demonstrators responding in English. About 15\% of the students insisted that demonstrators explaining in English did not help them as their command of English was poor and they would become more confused. They saw no benefit in having an isizulu-speaking demonstrator unless the entire lab was conducted in isizulu.

\section{Did you find the Physics tests difficult in terms of language and if so why?}

A quarter $(23 \%)$ of the respondents found the tests difficult because they did not understand the language of the questions and how to answer them. Only $5 \%$ of the students indicated that they were genuinely flummoxed by the questions because they did not understand what the English words 'derive', 'explain' or 'prove' meant. A majority (71\%) of the students found the tests easy to understand in terms of language but struggled with the physics component of the question or the mathematical computations and calculations.

\section{Did the isizulu-speaking tutors help you to better understand the work?}

Nearly $67 \%$ of the students reported that having isiZulu-speaking tutors helped them better understand the work. The use of their own language made it easy to ask questions on things they did not comprehend in English. Most students opted to go only to the tutorials that were run by isizulu-speaking tutors. They indicated that some of the tutors mixed isiZulu and English when explaining but they believed these tutorials still helped them to substantially improve.

A small percentage (19\%) of students said isiZulu-speaking tutors did not help because they still did not understand as the tutors used English throughout their explanations. A further 3\% indicated that they did not understand explanations in both English and isizulu and preferred only one language to be used.

\section{Do you think you would perform better if your notes were in isizulu?}

Close to $53 \%$ of the respondents believed they would perform better if their notes were in isizulu because they would feel more comfortable using their vernacular. Nearly $26 \%$ indicated that they would not perform any better, with their main concern being that some physics terms cannot be explained in isizulu and others do not even exist. A few students (4\%) said they were already accustomed to studying in English, so changing the language would not really change their performance. About $5 \%$ of students indicated that they are not proficient in isizulu, even though it is their first language.

\section{If your tests and exams were administered in isizulu, do you think it would improve your performance?}

Less than one-third (28\%) of the students agreed that being tested in isizulu would help their performance as they struggled to understand questions posed in English, even before attempting to answer the questions. This lack of understanding has cost them valuable time, hence if the questions were in isizulu, they would have more time to concentrate on the physics content of the question.

More than half $(55 \%)$ of the students said it would not help their performance if the assessments were in isizulu. These students said that they are already proficient in English and can explain more clearly in English than in isizulu because of difficulties in translating some English words to isizulu. These respondents were of the opinion that teaching science in isizulu must be introduced at school and the vocabulary developed and introduced when they are still young.

Do you think that being taught in isizulu would make physics easier to understand and thus improve your performance in the subject?

Just under half (49\%) of the students agreed that isizulu lectures would improve their understanding and performance because it would make it easier for them to ask questions in class and to interact with the teacher. 
A concern regarding accents (of non-isizulu first-language speakers) together with the issue of dialects was raised. The non-standard usage of terminology in isizulu to describe physics phenomena was also a major concern.

Over $40 \%$ of students said it would not help their performance because they have been communicating in English since primary school. Another $15 \%$ believed it might help with their performance but it would not make them competent in physics when compared to the rest of the world where English dominates physics communications.

\section{Is the English used in Physics lectures easy to understand?}

Almost $72 \%$ said they understand the language used in class as they are already accustomed to high school scientific communication in English; however, these students did have a problem understanding the physics concepts. About $23 \%$ attributed a lack of understanding of the English used in lectures to the pace of the lecturer's delivery, and thus found it difficult to absorb all that has been communicated. Some students said they get confused by some of the difficult terms that are used in physics.

\section{Have you ever used a dictionary (online or paper) to try to understand words you did not understand?}

Nearly $61 \%$ of students said they had used a dictionary to define words they did not understand, which helped them understand the lecture notes. About $28 \%$ have never used a dictionary before because they have not encountered words they did not understand. Others (11\%) said they used physics textbooks to define the physics terms they did not understand.

\section{Do you believe being taught in isizulu at university level is necessary?}

About one-third $(36 \%)$ of the students believed it is necessary to be taught in isizulu at university level to empower other students with poor English, especially those from rural areas, to equally participate in activities without being ashamed of their poor English. They felt that the full potential of these students was constrained by their inability to speak proper English.

Half $(51 \%)$ of the students suggested that it was unnecessary to be taught in isizulu. They believed that it would in fact create confusion because at university level there are many people who are not isizulu speaking. Instead they believe that those with poor English should learn and improve, like they had to, in order to communicate with others easily. A big concern raised by these respondents was the perceived affect on job opportunities because not all employers are likely to employ a graduate who is not proficient in English. Further they believed that because isizulu is not spoken internationally, there could be difficulties when looking for employment overseas.

However, $6 \%$ of the students believed that isizulu and English can both be used to make everyone comfortable, similarly to some universities in South Africa as well as overseas where they use both English and the local language as media of instruction.

A common trend observed from most of the responses to the idea of teaching and learning physics in isizulu is that it will produce graduates that cannot compete with the rest of the world because they cannot express themselves in English - English being officially recognised as the language of physics in most parts of the world.

To highlight the non-uniformity of the use of isizulu in physics, students were asked to translate a few English words commonly used in physics into isizulu. Table 4 shows their responses. The figure in parentheses is the percentage of students who translated the given word into each corresponding isizulu word. In each case, a large number of students could not translate the words into isizulu. The students all unanimously responded that no textbook for physics in isizulu was known to them.
Table 4: Students' responses when asked to translate common physics words from English to isizulu

\begin{tabular}{|c|c|c|}
\hline \multirow{2}{*}{$\begin{array}{l}\text { English word } \\
\text { Velocity }\end{array}$} & \multicolumn{2}{|l|}{ isiZulu translation } \\
\hline & $\begin{array}{l}\text { Isivinini } \\
\text { Ibanga } \\
\text { ljubane } \\
\text { Isipidi } \\
\text { Undelala oshesha nagayo } \\
\text { Ivelosithi }\end{array}$ & $\begin{array}{l}(52 \%) \\
(1 \%) \\
(5 \%) \\
(1 \%) \\
(2 \%) \\
(2 \%)\end{array}$ \\
\hline Speed & $\begin{array}{l}\text { ljubane } \\
\text { Isivinini } \\
\text { Izinga } \\
\text { Ukugijima } \\
\text { Ukushesha } \\
\text { Isantya } \\
\text { Isivivingo } \\
\text { Ukusheesha }\end{array}$ & $\begin{array}{l}(20 \%) \\
(45 \%) \\
(10 \%) \\
(1 \%) \\
(7 \%) \\
(1 \%) \\
(2 \%) \\
(4 \%)\end{array}$ \\
\hline Acceleration & $\begin{array}{l}\text { Ibanga } \\
\text { ljubane } \\
\text { Isivinini } \\
\text { Ekuphulo } \\
\text { Emfitho otakiwe } \\
\text { Ibonga louke } \\
\text { Indawo ewde } \\
\text { Indima } \\
\text { Ubude } \\
\text { Ukhalo } \\
\text { Umgama } \\
\text { Imnqansa }\end{array}$ & $\begin{array}{l}(1 \%) \\
(5 \%) \\
(18 \%) \\
(3 \%) \\
(3 \%) \\
(21 \%) \\
(21 \%) \\
(2 \%) \\
(13 \%) \\
(4 \%) \\
(2 \%) \\
(2 \%)\end{array}$ \\
\hline Distance & $\begin{array}{l}\text { Ibanga } \\
\text { Indima } \\
\text { Ubude } \\
\text { Ibonga louke } \\
\text { Indawo ewde } \\
\text { Ukhalo } \\
\text { Umgama } \\
\text { Imnqansa }\end{array}$ & $\begin{array}{l}(69 \%) \\
(2 \%) \\
(5 \%) \\
(2 \%) \\
(2 \%) \\
(4 \%) \\
(2 \%) \\
(2 \%)\end{array}$ \\
\hline Displacement & $\begin{array}{l}\text { Ibanga } \\
\text { Igebe } \\
\text { Indlela } \\
\text { Ubude } \\
\text { Ukuqhelelana } \\
\text { Ukungamulela } \\
\text { Indawo emfishane } \\
\text { Indima ekhaliwe } \\
\text { Indlela elula } \\
\text { Ubude } \\
\text { Uhambo } \\
\text { Ukuqhela }\end{array}$ & $\begin{array}{l}(13 \%) \\
(13 \%) \\
(1 \%) \\
(1 \%) \\
(4 \%) \\
(3 \%) \\
(2 \%) \\
(2 \%) \\
(2 \%) \\
(9 \%) \\
(2 \%) \\
(14 \%)\end{array}$ \\
\hline Mass & $\begin{array}{l}\text { Isisindo } \\
\text { Ukusinda } \\
\text { i-mass } \\
\text { isikalo }\end{array}$ & $\begin{array}{l}(77 \%) \\
(1 \%) \\
(12 \%) \\
(10 \%)\end{array}$ \\
\hline Length & $\begin{array}{l}\text { Ibanga } \\
\text { Indlendlana } \\
\text { Ubude } \\
\text { Ibubanzi }\end{array}$ & $\begin{array}{l}(3 \%) \\
(1 \%) \\
(78 \%) \\
(9 \%)\end{array}$ \\
\hline Pressure & $\begin{array}{l}\text { Ingcindezi } \\
\text { Amandla } \\
\text { Iphulesha } \\
\text { Umfutho } \\
\text { Incindezelo } \\
\text { Incindezi } \\
\text { Ukvcindezeleka } \\
\text { Ipresha } \\
\text { Emfutho } \\
\text { Umoya }\end{array}$ & $\begin{array}{l}(15 \%) \\
(2 \%) \\
(4 \%) \\
(6 \%) \\
(10 \%) \\
(31 \%) \\
(1 \%) \\
(1 \%) \\
(12 \%) \\
(13 \%)\end{array}$ \\
\hline Volume & $\begin{array}{l}\text { Isikhala } \\
\text { Uhubanzi } \\
\text { Ubukhulu } \\
\text { Ukuvhuleka } \\
\text { Umthamo } \\
\text { i-volumu } \\
\text { Inani } \\
\text { Iphuyinti } \\
\text { Ubaningi } \\
\text { Uhubanzi } \\
\text { Ubungako } \\
\text { Ukuvuleka }\end{array}$ & $\begin{array}{l}(6 \%) \\
(10 \%) \\
(8 \%) \\
(4 \%) \\
(4 \%) \\
(4 \%) \\
(6 \%) \\
(3 \%) \\
(1 \%) \\
(5 \%) \\
(4 \%) \\
(9 \%)\end{array}$ \\
\hline Density & $\begin{array}{l}\text { Idensithi } \\
\text { Isisindo } \\
\text { Incindezi } \\
\text { Ukugeleza kwento } \\
\text { Ukujiya } \\
\text { Isisindo } \\
\text { Isispace } \\
\text { Isizinda } \\
\text { Ubanjalo bento } \\
\text { Ubanzi } \\
\text { Ukuhlangana } \\
\text { Ukushuba }\end{array}$ & $\begin{array}{l}(6 \%) \\
(13 \%) \\
(2 \%) \\
(4 \%) \\
(6 \%) \\
(6 \%) \\
(1 \%) \\
(3 \%) \\
(1 \%) \\
(3 \%) \\
(11 \%) \\
(3 \%)\end{array}$ \\
\hline
\end{tabular}

The values in parentheses indicate the percentage of students who translated the English word into that particular isizulu word. 


\section{Conclusions}

The students' responses to the questions in the survey clearly convey mixed feelings surrounding the teaching of physics in isizulu. The majority feels that such an introduction should not be at university level but that teaching and learning physics (and science in general) in isizulu should be started when science is taught at primary schools. A common feeling was that a physics textbook in isizulu needs to be produced to provide a standard and uniform use of isizulu words for physics, and to define terms and other language nuances so as to comprehensively and accurately convey physics to isizulu speakers. Current usage of isizulu for physics is very convoluted - many physics words and terms are described by the same isizulu word, which then fails to convey the true physics meaning, thus adding to a student's misconception, which ultimately adversely affects performance.

The general conclusion of this study is that lectures should be conducted in English but supplemented by materials written in isizulu. Tutorials should make provision for students to be helped in isizulu if they so desire. The majority of students prefer to be examined in English while those that want to be examined in isizulu are also open to being examined in English as long as they understand (or are assisted to understand) the questions being asked.

This study has highlighted some important points by holistically considering students' backgrounds, schooling history and views on being taught physics in isizulu. Their comments and the results of this survey pave the way for future work to develop a textbook of physics in isizulu. Formalising isizulu for physics will enable students to conquer the huge divide that they sometimes face regarding language, and will hopefully help them improve their performance, consequently promoting more graduates within the sciences.

The work herein will be extended to quantitatively measure student performance in tests and assignments by comparing two cohorts those that receive language interventions and those that do not. Teaching in vernacular poses some unique challenges, but, being a multilingual society, we will need to constructively address these issues before proceeding to improve throughput, increase performance and graduate more students.

\section{Acknowledgements}

I thank my research assistants Ms Precious Dzapatsva and Ms Jayshree Naicker for help in conducting this research.

\section{References}

1. Logan PF. Language and physics. Physics Educ. 1981;6:74-77. http://dx.doi. org/10.1088/0031-9120/16/2/303

2. Logan PF. University physics teaching in a developing country. Physics Educ. 1978;13:442-445. http://dx.doi.org/10.1088/0031-9120/13/7/011

3. Bonwell CC, Eison JA. Active learning: Creating excitement in the classroom. Washington, DC: George Washington University School of Education and Human Development; 1991.

4. Chickering AW, Gamson ZF. Seven principles for good practice in undergraduate education. AAHE Bull. 1987;39(7):3-7.

5. Whorf BL. Language, thought and reality. New York: John Wiley; 1956.

6. Whorf BL. Linguistic relativity. London: Oxford University Press; 1973.

7. Skinner Q. Hobbes on representation. Eur J Philos. 2005;13:155-184. http:// dx.doi.org/10.1111/j.0966-8373.2005.00226.x

8. Dart FE. Science and the worldview. Phys Today. 1972;25(6):48. http:// dx.doi.org/10.1063/1.3070892

9. Logan PF. Physics in paradise. Phys Teach. 1976;14:81-85. http://dx.doi. org/10.1119/1.2339315

10. Pinker S. The language instinct. New York: Harper; 1994.

11. Casasanto D. Who's afraid of the Big Bad Whorf? Cross-linguistic differences in temporal language and thought. Lang Learn. 2008;58(1):63-79. http:// dx.doi.org/10.1111/j.1467-9922.2008.00462.x
12. Horton R. African traditional thought and Western science. In: Young MFD, editor. Knowledge and control. London: Collier Macmillan; 1971. p. 208-266.

13. Jones J. ERU report number 19 . Port Moresby: University of Papua New Guinea; 1976.

14. Friere P. Liberation through literacy. Port Moresby: University of Papua New Guinea; 1974.

15. Williams HT. Semantics in teaching introductory physics. Am J Phys. 1998;67:670-680. http://dx.doi.org/10.1119/1.19351

16. Lodhi AY. The language situation in Africa today. Nord J Afr Stud. 1993;2(1):79-86.

17. Whittle PA. Teaching physics in Uganda. Phys Educ. 1971;6:202-206. http:// dx.doi.org/10.1088/0031-9120/6/4/302

18. Fogel H, Ehri LC. Teaching elementary students who speak Black English vernacular to write in standard English: Effects of dialect transformation practice. Contemp Educ Psychol. 2000;25:212-235. http://dx.doi. org/10.1006/ceps.1999.1002

19. Bogden R, Biklen SK. Qualitative research for education. Boston: Allyn \& Bacon; 1992.

20. Hoepfl MC. Choosing qualitative research: A primer for technology education researchers. J Technol. 1997;9(1):12-39.

21. Chamot AU, El-Dinary PB. Children's learning strategies in immersion classrooms. Mod Lang J. 1999;83:319-341. http://dx.doi.org/10.1111/00267902.00025

22. El-Dib MAB. Language learning strategies in Kuwait: Links to gender, language level, and culture in a hybrid context. Foreign Lang Ann. 2004;37:85-95. http://dx.doi.org/10.1111/j.1944-9720.2004.tb02176.x

23. Green JM, Oxford R. A closer look at learning strategies, L2 proficiency, and gender. TESOL Quart. 1995;29(2):261-297. http://dx.doi.org/10.2307/ 3587625

24. Oxford RL, Burry-Stock JA. Assessing the use of language learning strategies worldwide with the ESL/EFL version of the Strategy Inventory for Language Learning. System. 1995;23(2):153-175. http://dx.doi.org/10.1515/iral. 2004.001

25. Chamot AU, Keatley C, Barnhardt S, El-Dinary PB, Nagano K, Newman C. Learning strategies in elementary language immersion programs. Washington DC: US Department of Education; 1996.

26. Chamot AU. The role of learning strategies in second language acquisition. In: Breen MP, editor. Learner contributions to language learning: New directions in research. Harlow, England: Longman; 2001. p. 25-43.

27. Oxford RL. Language learning strategies: What every teacher should know. New York: Newbury House; 1990.

28. Oxford R, Cho Y, Leung, S, Kim HJ. Effect of the presence and difficulty of task on strategy use: An exploratory study. Int Rev Appl Linguist. 2004;42:1-47.

29. Cohen AD, Weaver S, Li TY. Strategies in learning and using a second language. London: Longman; 1998.

30. Nyikos M, Oxford RL. A factor analytic study of language learning strategy use: Interpretations from information-processing theory and social psychology. Mod Lang J. 1993;7:11-22. http://dx.doi.org/10.1111/j.1540-4781.1993. tb01940.x

31. Olivares-Cuhat $\mathrm{G}$. Learning strategies and achievement in the Spanish writing classroom: A case study. Foreign Lang Ann. 2002;35(5):561-570. http:// dx.doi.org/10.1111/j.1944-9720.2002.tb02724.x

32. Oxford RL, Leaver BL. A synthesis of strategy instruction for language learners. In: Oxford RL, editor. Language learning strategies around the world: Cross-cultural perspectives. Honolulu, HI: University of Hawaii Press; 1996. p. 227-246.

33. Wharton G. Language learning strategy use of bilingualforeignlanguagelearners in Singapore. Lang Learn. 2000;50(2):203-244. http://dx.doi.org/10.1111/ 0023-8333.00117

34. National curriculum statement: Physical Sciences. Pretoria: Department of Basic Education; 2010. 